\title{
Intrathecal Tramadol for prevention of shivering in Anorectal surgeries under Sub arachnoid anaesthesia
}

\author{
Jain $\mathbf{S}^{1}$, Rohit $\mathbf{D}^{2}$, Arora $\mathrm{KK}^{3}$ \\ ${ }^{1}$ Dr Sarvesh Jain, Assistant Professor, Department Of Anesthesia, ${ }^{2}$ Dr Dushyant Rohit, Assistant Professor, Department Of \\ Surgery, ${ }^{3}$ Dr K K Arora, Professor, Department Of Anesthesia. All are affiliated with Bundelkhand Medical College, Sagar, \\ MP, India
}

Address for correspondence: Dr Sarvesh Jain, Email: jainvidisha7@yahoo.co.in

\begin{abstract}
Introduction: Shivering is very common problem during Sub arachnoid block (SAB), also known as Spinal anaesthesia. It can be prevented by intrathecal opioid injection. Material and method: In our study we have included 50 patients scheduled for anorectal surgery. They all were given spinal anaesthesia with bupivacaine $12.5 \mathrm{mg}$ along with injection Tramadol $10 \mathrm{mg}$ and watched for initial 4 hour. Result: 3 out of 50 patients showed shivering in treatment group who have received injection Tramadol. Discussion: Probable mechanism of action is its activity at mu receptor and serotonin and nor epinephrine reuptake inhibition. Conclusion: Intrathecal Tramadol in dose of $10 \mathrm{mg}$ prevents shivering in most of the patients. It can safely be used for prevention of shivering without significant side effect.
\end{abstract}

Keywords: Intrathecal Tramadol, Shivering, Sub arachnoid block, Tramadol, Spinal Anesthesia

\section{Introduction}

Shivering is a protective body mechanism to preserve core body temperature [1]. Shivering can be very unpleasant and physiologically stressful for the patients after enjoying the comforts of modern anesthetics. Mild shivering increases oxygen consumption to a level that is produced by light exercise, where as severe shivering increases metabolic rate and oxygen consumption up to $100-600 \%$. Shivering is very unpleasant, physiologically stressful for the patient undergoing surgery, and some patients find the accompanying cold sensation to be worse than the surgical pain. Though the mechanism of origin of shivering is not clear, various hypotheses have been proposed to explain its occurrence.

Perioperative hypothermia is the primary cause, which occurs due to neuraxial anaesthesia-induced inhibition of thermoregulatory mechanism. Shivering occurs as a thermoregulatory response to hypothermia or muscle activity with tonic or clonic patterns, and various frequencies have been noticed. However, in the postoperative period, muscle activity may be increased even with normothermia, suggesting that mechanisms other than heat loss with subsequent decrease in the core temperature contribute to the origin of shivering. These may be uninhibited spinal reflexes, sympathetic over-

\footnotetext{
Manuscript received: $04^{\text {rd }}$ Feb 2014

Reviewed: 05 $^{\text {th }}$ Feb 2014

Author Corrected: $13^{\text {th }}$ Feb 2014

Accepted for Publication: 10 $^{\text {th }}$ Mar 2014
}

International Journal of Medical Research and Review activity, postoperative pain, adrenal suppression, pyrogen release and respiratory alkalosis. Due to shivering and thermal discomfort, the quality of patient recovery suffers. Moreover, shivering per se may aggravate postoperative pain, simply by stretching of surgical incision.

Shivering is mediated by thermoregulatory centre in posterior hypothalamus near the wall of third ventricle. The processing of thermoregulatory response has three components: Afferent thermal sensing, Central regulation and efferent responses. Afferent thermal sensing Signals from cold receptors travel along delta fibers and signals from warmth receptors are conveyed by $\mathrm{C}$ fibers. Thermal inputs get integrated at the level of spinal cord, thermoregulatory effector mechanisms are modulated by spinal cord, eventually it arrives at the hypothalamus, the primary thermoregulatory control center.

In Humans a thermoregulatory system coordinates defenses against environmental Temperature to maintain internal body temperature within a narrow range, thus. Anesthetic induced thermoregulatory impairment and exposure to a cool environment makes most unwarmed surgical patients hypothermic [2].

It has strong association with volatile anesthetics and sub arachnoid block. Anesthetic drug induced peripheral vasodilatation is responsible factor [2, 3]. It has

Available online at: $\underline{\text { www.ijmrr.in }} 190$ | P a g e 
Research Article

significant impact on surgical outcome. Vigorous shaking intra operatively or post operatively, can increase metabolic oxygen consumption multiple times. It is related with adverse myocardial outcome, raises intra ocular and intra cranial pressure and can cause significant metabolic acidosis $[4,8]$.

Sub arachnoid block or spinal anaesthesia is most common type of method used for anorectal surgery. Ease of administration, relatively few contraindication and good anal sphincter relaxation makes it preferred method of anaesthesia for anorectal surgeries. Intrathecal opioids are used to prolong analgesic effect and to prevent shivering intra operatively and post operatively

For this purpose Morphine, pethidine, fentanyl, sufentanyl and Tramadol can be used. Other agents which can be given intrathecally are neostigmine and midazolam.To prevent shivering intravenous use of ketamine, magnesium sulphate and clonidine can also be done [4-6].

\section{Method and material}

This study was done at Bundelkhand Medical college Hospital and associated District hospital, sagar (MP) in winters between November 2011 \& February 2012. We chose winters for our study as occurrence of shivering is more due to low ambient temperature, so it will precisely demonstrate the efficacy of our intervention

After Institutional Ethical Committee approval and written informed consent we took 50 patient of 25 to 60 years of age (ASA Grade I) and they all were having anorectal disease (Hemorrhoids, Anal fissure and anal fistula). 38 were male. All the patients were of mixed socioeconomic status and of Indian ethnicity.

\section{Exclusion criteria}

Patients with prior history of coronary artery disease, hypertension, diabetes mellitus, suspected intracranial pathology, morbid obesity, Psychiatric disorder, substance dependence and any other systemic illness were excluded from study. Patients who were taking vasodilators/vasoconstrictors were not included in the study as those drugs could interfere with the body thermoregulation
All operations were performed in the same operation theater, which was maintained at a constant humidity and an ambient temperature of around $22 \pm 2{ }^{\circ} \mathrm{C}$. The operating room was not equipped to provide laminar flow each patient received $500 \mathrm{ml}$ of warmed ringer lactate (RL) (37 degree Celsius) before putting spinal anaesthesia.

Each patients received $12.5 \mathrm{mg}$ of bupivacaine (heavy) mixed with $10 \mathrm{mg}$ Tramadol (preservative free) at L3-L4 inter- space with 23 gauze spinal needle in sitting position and monitored with triple Para monitor (pulse, Blood pressure and $\mathrm{SP} 02$ ) at 5 minute of interval, up to conclusion of surgery. Then half hourly monitoring was done for next 4 hour.

After positioning in lithotomy position, patients were covered with standard hospital supply, small blanket (used for pediatric purpose) from navel to neck (not actively warmed)

During surgery, each patient received $500 \mathrm{ml}$ of warmed $\mathrm{RL}$ and $500 \mathrm{ml}$ of warmed dextrose $5 \%$ in post operative period After shifting each patient was covered with single layered hospital supply adult size blanket. And observed for shivering and Post operative Nausea vomiting

After putting spinal anaesthesia, each patient was observed for 4 hours (including surgical time) for shivering

We assessed Post anesthetic shivering according to Crossley and mahajan shivering scale [7].

$$
\begin{aligned}
& 0=\text { no shivering; } \\
& 1=\text { no visible muscle activity but piloerection, } \\
& \text { peripheral vasoconstriction, or both are present } \\
& \text { (other causes excluded); } \\
& 2=\text { muscular activity in only one muscle group; } \\
& 3=\text { moderate muscular activity in more than one } \\
& \text { muscle group but no generalized shaking; } \\
& 4=\text { violent muscular activity that involves the } \\
& \text { whole body. }
\end{aligned}
$$

\section{Results}

In initial 4 hours, after putting $\mathrm{SAB}$, out of 50 patients only 3 showed shivering

Out of 3, one patient showed moderate shivering (grade 3 on Crossley and Mahajan, Post anesthetic shivering scale)

And two showed grade 2 shivering. None of the patient reported, any kind of nausea or vomiting 
Table 1: Number of patients showed shivering 4 hours after putting SAB

\begin{tabular}{|c|c|c|c|c|}
\hline $\begin{array}{c}\text { Total } \\
\mathrm{Pt}\end{array}$ & No shivering & Mild shivering & Moderate shivering & Severe shivering \\
\hline 50 & 47 & 2 & 1 & Nil \\
\hline
\end{tabular}

\section{Discussion}

Regional anaesthesia, either central neuraxial block or peripheral nerve block, is a safe and very popular technique used for various surgeries. However, $40 \%$ to $70 \%$ of patients undergoing regional anaesthesia develop shivering, though it is also found to occur after general anaesthesia. Post anesthetic shivering is a very common consequence in immediate post operative period, in post general anaesthesia patients it is mostly because of volatile anesthetic induced thermoregulatory centre inhibition. In post neuroaxial blockade patients it is mostly due to peripheral vasodilation [8]

It is related with increased risk of myocardial infarction, cerebral stroke, raised intracranial pressure, increased intraocular pressure. It interferes with ECG and pulse oxymetric interpretation. In severe cases it can cause metabolic acidosis.

There are two type of method s to prevent shivering, one is non pharmacological in which forced air warming is most effective method [8]. Non-pharmacological methods using equipments to maintain normothermia are effective but may be expensive and are not practical in all the settings.

In our study, we tested pharmacological method to prevent shivering i.e. by using Tramadol in intrathecal space along with bupivacaine Tramadol is synthetic codeine analog that is the weak $\mathrm{Mu}$ opioid receptor agonist, part of its analgesic effect is produced by inhibition of uptake of nor epinephrine and serotonin. In the treatment of mild to moderate pain tramadol is as effective as morphine or meperidine [9-11].

Postulated hypothesis is, it's interaction with mu opioid receptor at spinal cord but action at supraspinal level may also contribute. Tramadol is nor epinephrine and serotonin reuptake inhibitor also, this action can also be responsible for anti shivering effect because opioid antagonist naloxone only partially reverse the anti shivering effect of Tramadol.

In $94 \%$ of patients, intrathecal Tramadol effectively prevented the onset of shivering, and literature suggests that $40 \%$ to $70 \%$ of patients undergoing regional anaesthesia, show shivering post operatively. In

International Journal of Medical Research and Review remaining $6 \%$, it was not proved effective. Mohta $\mathrm{M}$ et al in their study found that intra venous Tramadol $10 \mathrm{mg}$ had the best combination of antishivering and analgesic efficacy without excessive sedation and thus appeared to be a good choice to be administered at the time of wound closure to provide antishivering effect and analgesia without significant side effects in the postoperative period [12].

Sadegh et al used intrathecal fentanyl instead of Tramadol and find it beneficial for prevention of shivering and postulated its effect on thermoregulatory centre and on spinal cord thermal input [13].

Tewari et al concluded that the use of oral Tramadol 50 $\mathrm{mg}$ is effective as a prophylactic agent to reduce the incidence, severity and duration of perioperative shivering in patients undergoing TURP surgery under SAB [14].

Similarly in our study we found that intrathecal Tramadol is significantly effective for prevention of shivering in anorectal surgeries

In $10 \mathrm{mg}$ dose there is little possibility of side effect peculiar to Tramadol like nausea and vomiting. Effect of Bupivacaine in SAB block, wears off in 4 hours, so after that chance of further shivering is less, although not studied in present study

\section{Conclusion}

Intrathecal Tramadol is safe, reliable and cost effective adjuvant to spinal anaesthesia. It effectively prevents intra and post operative shivering. None of the patient reported any kind of nausea or vomiting. This was a small sized study; larger studies are required to fully validate this theory.

\section{Funding: Nil}

\section{Conflict of interest: Nil}

\section{Permission from IRB: Yes}

\section{References}

1. Barash PG, Cullen BF, Stoelting RK. Clinical Anesthesia; $5^{\text {th }}$ Edition: Lippincott Williams \& Wilkins; 2006, 1400 .

Available online at: $\underline{\text { www.ijmrr.in }} 192$ | P a g e 
2. Bhattacharya PK, Bhattacharya L, Jain RK, Agarwal RC. Post Anaesthesia Shivering: A Review. Indian J. Anaesthesia. 2003; 47 (2): 88-93.

3. Eberhart LH, Döderlein F, Eisenhardt G, Kranke P, Sessler DI, Torossian A, Wulf H, Morin AM. Independent Risk Factors for Postoperative Shivering. Anesth Analg. 2005 Dec;101(6):1849-57.

4. Morgan GE, Mikhail MS, Murray MJ. Clinical Anesthesiology: Lange Medical Books/McGraw Hill; 2006, 1008-9.

5. Alfonsi, P. Postanaesthetic shivering: epidemiology, pathophysiology, and approaches to prevention and management. Minerva Anestesiol. 2003 May;69(5):43842

6. Peter Kranke, Leopold H E, Norbert Roewer, Martin R. Trame. Pharmacological Treatment of Postoperative Shivering: A Quantitative Systematic Review of Randomised Controlled Trials. AnesthAnalg 2002; 24 : $453-60$.

7. Crossley AW, Mahajan RP. The intensity of postoperative shivering is unrelated to axillary temperature. Anaesthesia. 1994;49:205-07.
8. CrowleyLJ, Buggy DL, Shivering and neuraxia 1 anaesthesia. Regional Anesthesia and Pain Medicine 2008; 33(3):241-52

9. Ronald D miller ,Miller's anesthesia, $6^{\text {th }}$ ed, Churchill living stone,(p1580)

10. Rang and dales Pharmacology,churchil livingstone, $6^{\text {th }}$ edi(p 605)

11. Goodman and gilman's pharmacological basis for therapeutics, $12^{\text {th }}$ edi,p 1023.

12. Mohta M, Kumari N, Tyagi A, Sethi AK, Agarwal D, Singh MTramadol for prevention of postanaesthetic shivering: a randomised double-blind comparison with pethidine. Anaesthesia. 2009 Feb;64(2):141-6.

13. Ali Sadegh, Nasrin Faridi Tazeh-kand, Bita Eslami. Intrathecal fentanyl for the prevention of shivering in spinal anaesthesia in caesarean section. Med J Islam Repub Iran. May 2012; 26(2): 85-89.

14. Tewari A,dhawan I.etal "use of oral tramadol to prevent perianesthetic shivering in patients undergoing transurethral resection of prostate under subarachnoid blockade,". saudi journal of Anaesthesia, 2014;8(1):11-16

\section{How to cite this article?}

Jain S, Rohit D, Arora KK. Intrathecal Tramadol for prevention of shivering in Anorectal surgeries under Sub arachnoid anaesthesia. Int J Med Res Rev 2014;2(3):190-193.doi:10.17511/ijmrr.2014.i03.04 